\title{
Letter to the Editor: Does Combined Anterior- Posterior Approach Improve Outcomes Compared with Posterior-only Approach in Traumatic Thoracolumbar Burst Fractures?: A Systematic Review
}

\author{
K. Guna Pratheep, Vibhu Krishnan Viswanathan \\ Department of Spine Surgery, Ganga Medical Centre and Hospital Pvt. Ltd., Coimbatore, India
}

With great interest, we read the article by Tan et al. [1] "Does combined anterior-posterior approach improve outcomes compared with posterior-only approach in traumatic thoracolumbar burst fractures?: a systematic review." It is a systematic review involving five retrospective cohort studies comparing combined anterior-posterior and posterior-only approaches for traumatic thoraco-lumbar (TL) burst fractures. It is a well-written article, and the authors' efforts to comprehensively discuss various outcome factors are commendable. However, we would like to put forth some clarification and queries regarding this article.

(1) Our main concern is regarding the study methodology employed in this meta-analysis. The authors have only included the studies which had already made a comparison between combined anterior-posterior and posterioronly approaches for TL burst fractures. Using this search criterion, only five articles could be included for the final analysis and discussion. Even among these five articles, three were published at least 15 years earlier [2-4].
We believe that a better methodology would have been to include all studies which had discussed either posterior-only or combined anterior-posterior approaches. On a superficial search made by us on Medline database using such a strategy, we could identify at least 52 studies (43 studies discussing posterior-only approach versus nine studies on combined anterior-posterior approach). Using such a selection criterion, the authors could have analyzed their results in a larger group of patients, which would have made the entire study much more valuable.

(2) Based on the same rationale discussed above, if the study methodology would have been different as indicated, we could have also included a greater number of more recent studies. With the advent of specialized technology and sophisticated techniques of anterior and posterior spinal fixations, the field of spinal surgery has undergone a sea of changes over the past decade. Unfortunately, the search strategy employed has only yielded two articles in this time period $[5,6]$. Would this alternative search strategy have changed the outcome of this systematic review?

Received Jul 22, 2020; Accepted Jul 22, 2020

Corresponding author: Vibhu Krishnan Viswanathan

Department of Spine Surgery, Ganga Medical Centre \& Hospital Pvt. Ltd., Coimbatore, Tamil Nadu, India

Tel: +91-7358622093, E-mail: drvibu007@gmail.com 
(3) Again, minimally-invasive spinal procedures have flourished over the past few years. These procedures have become much more relevant in the management of spinal trauma in the present-day scenario than ever before. These approaches have the made the anterior/lateral procedures much less morbid and more surgeon-friendly. If studies involving minimally-invasive approaches to the spine had also been considered (using the alternate search criterion), results could have been better analyzed.

Despite these aforementioned concerns, we do appreciate immensely the efforts of the authors in putting forth such an interesting article on this relevant subject.

\section{Conflict of Interest}

No potential conflict of interest relevant to this article was reported.

\section{References}

1. Tan T, Donohoe TJ, Huang MS, et al. Does combined anterior-posterior approach improve outcomes compared with posterior-only approach in traumatic thoracolumbar burst fractures?: a systematic review. Asian Spine J 2020;14:388-98.
2. Been HD, Bouma GJ. Comparison of two types of surgery for thoraco-lumbar burst fractures: combined anterior and posterior stabilisation vs. posterior instrumentation only. Acta Neurochir (Wien) 1999;141:349-57.

3. Briem D, Lehmann W, Ruecker AH, Windolf J, Rueger JM, Linhart W. Factors influencing the quality of life after burst fractures of the thoracolumbar transition. Arch Orthop Trauma Surg 2004;124:4618.

4. Danisa OA, Shaffrey CI, Jane JA, et al. Surgical approaches for the correction of unstable thoracolumbar burst fractures: a retrospective analysis of treatment outcomes. J Neurosurg 1995;83:977-83.

5. Mayer M, Ortmaier R, Koller H, et al. Impact of sagittal balance on clinical outcomes in surgically treated T12 and L1 burst fractures: analysis of long-term outcomes after posterior-only and combined posteroanterior treatment. Biomed Res Int 2017;2017:1568258.

6. Schmid R, Lindtner RA, Lill M, Blauth M, Krappinger D, Kammerlander C. Combined posteroanterior fusion versus transforaminal lumbar interbody fusion (TLIF) in thoracolumbar burst fractures. Injury 2012;43:475-9. 